\title{
Fludrocortisone for Treatment of Intradialytic Hypotension: Case Report and Review of Literature
}

\author{
Nasser Mikhail \\ Endocrinology Division, Department of Medicine, Olive-View-UCLA Medical School, David-Geffen UCLA School of Medicine, \\ Sylmar, CA, USA.
}

\begin{abstract}
How to cite this paper: Nasser Mikhail. (2021) Fludrocortisone for Treatment of Intradialytic Hypotension: Case Report and Review of Literature. International Journal of Clinical and Experimental Medicine Research, 5(3), 383-386. DOI: 10.26855/ijcemr.2021.07.024

Received: June 17, 2021

Accepted: July 12, 2021

Published: July 27, 2021

*Corresponding author: Nasser Mikhail, Endocrinology Division, Department of Medicine, Olive-View-UCLA Medical School, David-Geffen UCLA School of Medicine, Sylmar, CA, USA. Email: nmikhail@dhs.lacounty.gov
\end{abstract}

\begin{abstract}
Background: Intradialytic hypotension (IDH) is a common complication of hemodialysis (HD). Pharmacologic treatment options are limited in terms of number and efficacy. Objective: To report a case of IDH that responded to fludrocortisone. Similar cases and pertinent literature were reviewed. Methods: Pubmed research of English literature up to June 16, 2021. Search terms included, hemodialysis, hypotension, intradialytic hypotension, midodrine, fludrocortisone, droxidopa, safety, efficacy. Retrospective studies, case report and series, Cochrane reviews, randomized trials are reviewed. Results: Midodrine and droxidopa are approved by the Federal Drug Administration (FDA) for treatment of orthostatic hypotension, but not for IDH. No randomized trials are available to evaluate midodrine for IDH. One large retrospective study suggests that midodrine use for treatment of IDH may be associated with increase death and hospitalization. Results of a single randomized phase 2 trial suggest that droxidopa may not be effective in IDH. The author reports a 63-year-old patient with IDH who failed midodrine but responded to the addition of fludrocortisone. Review of literature revealed 3 other similar cases, No short-term adverse effects of fludrocortisone were reported in any of these 4 cases. Conclusions: Pharmacological options available for treatment of IDH are limited and inadequately studied. Fludrocortisone appears a promising agent to prevent IDH in patients failing midodrine. Randomized trials are needed to compare efficacy and safety of midodrine and fludrocortisone and their combination for management of IDH.
\end{abstract}

\section{Keywords}

Fludrocortisone, Intradialytic Hypotension, Midodrine, Droxidopa

\section{Introduction}

Depending on its definition, the prevalence of intradialytic hypotension (IDH) ranges from $10 \%$ to $50 \%$ of patients undergoing hemodialysis (HD) [1]. The National Kidney foundation defines IDH as a decrease in systolic blood pressure (SBP) by $\geq 20 \mathrm{mmHg}$ or a decrease mean arterial blood pressure of $10 \mathrm{mmHg}$ associated with symptoms [2]. Some experts define IDH as a function of corrective measures such as administration of normal saline, or reduction in ultrafiltration volume [3]. Interestingly, IDH may be associated with increased risk of death [4]. Flythe et al. [5] studied the associations of various definitions of IDH with mortality. They found that an absolute 
nadir SBP $<90 \mathrm{mmHg}$ was most potently associated with mortality. Thus, adjusted odds ratio (OR) of 2-year mortality was 1.56 (95\%CI 1.05-2.31) for patients with nadir SBP $<90 \mathrm{mmHg}$ versus those who had not such drop in SBP [5]. Despite the common occurrence of IDH and its link to increased death, very limited pharmacologic options exist. In fact, there are no approved drugs by the FDA in the US to prevent or treat IDH. Currently, most cases of IDH are treated with midodrine given 10-30 min before dialysis. The purpose of this article is to draw attention to fludrocortisone as potential effective and safe drug for treatment of IDH.

\section{Case report}

A 63 y/o anuric man with end-stage renal disease on hemodialysis for 11 years presenting with asymptomatic IDH, with SBP frequently dropping to below $90 \mathrm{mmHg}$ during HD sessions. Patient had severe anemia (his hemoglobin was 7.3-8.0 g/dl, normal: 13.5-16.5 g/dl) being treated with subcutaneous darbepoetin alfa 40 mcg weekly and oral iron sulfate. Other comorbidities included a history of myocardial infarction and coronary artery bypass surgery. Several approaches were undertaken to correct this hypotension including midodrine $10 \mathrm{mg}$ given 10-15 min before each dialysis session and infusion of albumin $25 \mathrm{gm}$ and normal saline. In addition, the HD sessions were terminated prematurely on many occasions after 1.8-2 h. As a result, the ultrafiltrate achieved was less than planned ranging 1.8-2 liters/HD session. Endocrine service was consulted. Thus, endocrine causes of hypotension such as diabetes and adrenal insufficiency were ruled out by normal hemoglobin A1c levels (4.8\%, normal $<5.6 \%)$, and appropriate response to the cosyntropin stimulation test, respectively. The author therefore recommended adding fludrocortisone $0.1 \mathrm{mg}$ orally every morning. Two days later, fludrocortisone dose was increased to $0.2 \mathrm{mg}$ every morning as blood pressure did not increase with the smaller dose. Patient responded to the $0.2 \mathrm{mg}$ dose within few days, and no hypotension was recorded in the subsequent HD sessions. Review of literature revealed only 3 similar patients in whom fludrocortisone was used to treat IDH (see Table 1). Interestingly, in all patients including ours, blood pressure failed to respond to midodrine alone and responded to the addition of fludrocortisone.

Table 1. Reported cases of intra-dialysis hypotension treated with fludrocortisone

\begin{tabular}{|c|c|c|c|c|}
\hline Reference & Mercadal et al. [6] & Mercadal et al. [6] & Seo et al. [7] & Current case \\
\hline Age and gender & $\begin{array}{l}\text { 50- year-old wom- } \\
\text { an }\end{array}$ & 68-year-old-man & 66-year-old woman & 63-year-old man \\
\hline Comorbidities & $\begin{array}{l}\text { Diabetes, history of } \\
2 \text { myocardial in- } \\
\text { farctions }\end{array}$ & $\begin{array}{l}\text { History of myocar- } \\
\text { dial infarction }\end{array}$ & Diabetes & $\begin{array}{l}\text { Ischemic cardiomyopathy, } \\
\text { history of coronary bypass } \\
\text { graft, anemia. }\end{array}$ \\
\hline Midodrine status & $\begin{array}{l}\text { Patient was resis- } \\
\text { tant to midodrine }\end{array}$ & $\begin{array}{l}\text { Patient was resistant } \\
\text { to midodrine }\end{array}$ & $\begin{array}{c}\text { No response to midodrine } 10 \\
\text { mg before dialysis after } 2 \text { years } \\
\text { of use }\end{array}$ & $\begin{array}{l}\text { No response to midodrine } \\
10 \mathrm{mg} \text { before dialysis }\end{array}$ \\
\hline $\begin{array}{l}\text { Fludrocortisone } \\
\text { regimen }\end{array}$ & Not reported & 0.5 mg qday & $\begin{array}{c}0.2 \mathrm{mg} 3 \text { times a week } 30 \mathrm{~min} \\
\text { before dialysis. }\end{array}$ & 0.2 mg qday \\
\hline $\begin{array}{l}\text { Response to flu- } \\
\text { drocortisone }\end{array}$ & $\begin{array}{l}\text { Improvement in } \\
\text { post-dialysis *SBP }\end{array}$ & $\begin{array}{l}\text { Improvement in } \\
\text { post-dialysis *SBP }\end{array}$ & Improvement in *SBP & $\begin{array}{l}\text { Improvement in in- } \\
\text { tra-dialysis *SBP }\end{array}$ \\
\hline Adverse effects & None & None & None & None \\
\hline $\begin{array}{l}\text { Effects on inter- } \\
\text { dialytic weight } \\
\text { gain }\end{array}$ & Decrease & Decrease & $\begin{array}{l}\text { Decrease from mean (SD) } 2.9 \\
\text { (4.7) to } 2.0(0.6) \mathrm{kg}\end{array}$ & No effect \\
\hline $\begin{array}{l}\text { Effects on serum } \\
\text { potassium }\end{array}$ & Not reported & Not reported & $\begin{array}{c}\text { Correction of hyperkalemia } \\
\text { from } 6.3(0.2) \text { before to } 5.4 \\
(0.4) \mathrm{mmol} / \mathrm{L} \text { after fludrocorti- } \\
\text { sone }(\mathrm{P}=0.029) \text {. }\end{array}$ & No significant effect \\
\hline
\end{tabular}

*SBP systolic blood pressure

\section{Use of fludrocortisone for treatment of intradialytic hypotension}

Fludrocortisone is a synthetic mineralocorticoid that enhances sodium reabsorption in distal renal tubules leading to increase in intravascular volume and rise in blood pressure [8, 9]. In addition, Davies et al. [10] have shown that it may augment the sensitivity to the pressor effect of noradrenaline. Although fludrocortisone is probably the commonest drug used to treat orthostatic hypotension, it is not approved by the FDA for that purpose [8]. Moreover, 
there are no available studies to evaluate fludrocortisone specifically for treatment of IDH. A recent Cochrane review found that fludrocortisone was evaluated in 13 crossover and observational studies for treatment of orthostatic hypotension in patients with diabetes and Parkinson disease [11]. The authors of the latter review concluded that available evidence was very uncertain about the effects of fludrocortisone on blood pressure, orthostatic symptoms or adverse effects in these 2 diseases [11]. Thus, fludrocortisone remains inadequately studied despite being an old drug.

\section{Safety profile of fludrocortisone}

Adverse effects associated with fludrocortisone may be predicted from its mechanism of action. Thus, its salt-retaining action may result in edema, hypernatremia, and if severe, congestive heart failure [9]. In the author's experience, hypokalemia appears to be the most common adverse effect of fludrocortisone due to its stimulatory effect on potassium excretion [9]. Hypokalemia is dose-related and occurs early within few days of administration, persists with long-term use of fludrocortisone, and frequently require potassium supplementation and high potassium diet [12]. Other adverse effects reported are headache insomnia and increase sweating [11]. Since adverse effects increase with the dose, it is reasonable to start fludrocortisone with $0.1 \mathrm{mg}$ qday, then increase the dose after few days to $0.2 \mathrm{mg}$ qday if no blood pressure response was seen similar to the strategy applied in our patient. It is reassuring that no adverse effects were reported in any of the 4 patients who received fludrocortisone before dialysis (see Table 1). Specifically, hypokalemia did not occur in any of the 4 patients, most likely due to the underlying end-stage kidney disease. In one retrospective study of Tennessee Medicaid enrollees, users of fludrocortisone had higher rates of all-cause hospitalizations compared with users of midodrine (adjusted incidence-rate ratio 1.20, 95\% CI, 10.2-1.40) [13]. However, patients on hemodialysis were excluded from the previous study [13]. Long-term safety of fludrocortisone is not well studied. In an early study, Chobanian et al. [12] followed a case series of 7 patients with orthostatic hypotension treated with fludrocortisone for 1-14 years. During follow-up, 2 patients developed hypertensive retinopathy [12]. However, this study did not include a placebo group and the doses of fludrocortisone were much higher than currently recommended ranging from 0.3 to $1.0 \mathrm{mg} / \mathrm{d}$ [12].

\section{Midodrine}

Midodrine is a prodrug of the $\alpha-1$ adrenergic receptor agonist desglymidodrine [14]. The latter raises blood pressure by causing vasoconstriction of both arterioles and veins [14]. Midodrine (proamatine) was approved the FDA in 1996 for treatment of symptomatic orthostatic hypotension $[8,15]$. Despite the absence of randomized trials to evaluate efficacy and safety of midodrine for management of IDH, this drug is often administered 10-30 min before HD to prevent and treat IDH [16]. In a meta-analysis of 10 small studies including a total of 117 patients on HD, Prakash et al. [14] found that 6 of 10 studies reported amelioration in symptoms of IDH with use of midodrine. Meanwhile, in a large retrospective study, Brunelli et al. [17] compared hard outcomes of patients on HD who were prescribed midodrine $(\mathrm{n}=1,046)$ with matched patients not using midodrine $(\mathrm{n}=2,037)$. Compared with non-use, midodrine use was associated with higher rates of death [adjusted incidence rate ratio (RR) 1.37, 95\% CI, 1.15-1.62], all-cause hospitalization (RR 1.31, 95\% CI 1.19-1.43) and cardiovascular hospitalization (RR 1.41, 95\% CI 1.17-1.71) [17]. Moreover, midodrine use tended to be associated with lower pre-dialysis SBP, lower nadir SBP and greater fall of in SBP during HD [17]. These results, although limited by being retrospective, suggest that midodrine is unlikely to be beneficial in treatment of IDH, and may even be harmful.

\section{Droxidopa}

Droxidopa (Northera) is a prodrug that is converted to norepinephrine causing vasoconstriction and rise in blood pressure. It was approved by the FDA in 2014 for the treatment of symptomatic neurogenic orthostatic hypotension caused by primary autonomic failure [18]. Several studies from Japan evaluated droxidopa for treatment of hypotension. In one randomized study, Akizawa et al. [19] found significant rise in SBP and diastolic blood pressure measured within 10 minutes after completion of HD compared with pre-treatment levels. However, changes in intra-hemodialysis blood pressure were not evaluated. In the USA, a randomized phase-2 study conducted by Vannorsdall et al. [20] failed to record significant difference in intra-hemodialysis mean arterial pressure, the study primary outcome, between patients receiving droxidopa and those receiving placebo. Similarly, no significance differences were found in hypotension-induced symptoms between the droxidopa and placebo groups [20]. Taken together, available data suggest that droxidopa may not be effective as treatment of IDH. 


\section{Conclusion and current needs}

Although IDH is a common complication of HD that carries unfavorable prognosis, very limited data exists regarding to its pharmacological therapy. At present, midodrine seems to be the commonest drug used to manage IDH. However, its efficacy and safety in this setting are not properly evaluated. Furthermore, results of a large retrospective study suggest that midodrine might increase mortality and hospitalization rates when used to treat IDH. The 4 cases reported here suggest that fludrocortisone could be effective and safe at least on short-term to treat IDH in patients failing midodrine. Randomized trials are urgently needed to evaluate efficacy and safety of fludrocortisone in patients with hypotension in general, and those with IDH in particular. These trials should compare fludrocortisone with placebo and with other drugs approved for treatment of orthostatic hypotension such as midodrine. Since the mechanisms of action are different, it would be equally important to evaluate efficacy and safety of the combination of fludrocortisone and midodrine in the setting of IDH.

\section{Conflict of interest}

The author has no conflict of interest to declare.

\section{References}

[1] Assimon, M. M., Flythe, J. E. (2017). Definitions of intradialytic hypotension. Semin Dial., 2017, 30(6): 464-472.

[2] K/DOQI Workgroup. (2005). K/DOQI clinical practice guidelines for cardiovascular disease in dialysis patients. Am J Kidney Dis., 2005, 45(4 Suppl 3): S1-153.

[3] Reeves, P. B., Mc Causland, F. R. (2018). Mechanisms, Clinical Implications, and Treatment of Intradialytic Hypotension. Clin J Am Soc Nephrol., 2018, 13(8): 1297-1303.

[4] Shoji, T., Tsubakihara, Y., Fujii, M., Imai, E. (2004). Hemodialysis-associated hypotension as an independent risk factor for two-year mortality in hemodialysis patients. Kidney Int., 2004 Sep, 66(3): 1212-20.

[5] Flythe, J. E., Xue, H., Lynch, K. E., Curhan. G. C., Brunelli, S. M. (2015). Association of mortality risk with various definitions of intradialytic hypotension. J Am Soc Nephrol., 2015 March, 26(3): 724-34.

[6] Mercadal, L., Petitclerc, T. (2005). Effect of mineralocorticoids on interdialytic weight gain in hemodialysis patients with perdialytic hypotension. Hemodial Int., 2005, 9(4): 338-40.

[7] Seo, Y., Jeung, S., Kang, S. M., Yang, W. S., Kim, H., Kim, S. B. (2018). Use of fludrocortisone for intradialytic hypotension. Kidney Res Clin Pract., 2018, 37(1): 85-88.

[8] Palma, J. A., Kaufmann, H. (2020). Management of Orthostatic Hypotension. Continuum (MinneapMinn). 2020, 26(1): 154-177.

[9] Freeman, R. (2008). Clinical practice. Neurogenic orthostatic hypotension. N Engl J Med., 2008, 358(6): 615-24.

[10] Davies, I. B., Bannister, R. G., Sever, P. S., Wilcox, C. S. (1978). Fludrocortisone in the treatment of postural hypotension: altered sensitivity to pressor agents [proceedings]. Br J Clin Pharmacol., 1978, 6(5): 444P-445P. PMID: 728295.

[11] Veazie, S., Peterson, K., Ansari, Y., Chung, K. A., Gibbons, C. H., Raj, S. R., Helfand, M. (2021). Fludrocortisone for orthostatic hypotension. Cochrane Database Syst Rev., 2021, 5(5): CD012868.

[12] Chobanian, A. V., Volicer, L., Tifft, C. P., Gavras, H., Liang, C. S., Faxon, D. (1979). Mineralocorticoid-induced hypertension in patients with orthostatic hypotension. N Engl J Med., 1979, 301(2): 68-73.

[13] Grijalva, C. G., Biaggioni, I., Griffin, M. R., Shibao, C. A. (2017). Fludrocortisone Is associated with a Higher risk of all-cause hospitalizations compared with midodrine in patients with orthostatic hypotension. J Am Heart Assoc., 2017, 6(10): e006848.

[14] Prakash, S., Garg, A. X., Heidenheim, A. P., House, A. A. (2004). Midodrine appears to be safe and effective for dialysis-induced hypotension: a systematic review. Nephrol Dial Transplant, 2004, 19(10): 2553-8.

[15] Proamatine (midodrine). Prescribing information 2017. Shire US Inc. Lexington, MA, USA.

[16] Hammes, M., Bakris, G. L. (2018). Intradialytic Hypotension: Is Midodrine the Answer? Am J Nephrol., 2018, 48(5): 378-380.

[17] Brunelli, S. M., Cohen, D. E., Marlowe, G., Van Wyck, D. (2018). The Impact of Midodrine on Outcomes in Patients with Intradialytic Hypotension. Am J Nephrol., 2018, 48(5): 381-388.

[18] Northera (Droxidopa) prescribing information. Chelsea Therapeutics, Inc. Charlotte, NC, 2014.

[19] Akizawa, T., Koshikawa, S., Iida, N., Marumo, F., Akiba, T., Kawaguchi, Y., Imada, A., Yamazaki, C., Suzuki, M., Tubakihara. Y. (2002). Clinical effects of L-threo-3,4-dihydroxyphenylserine on orthostatic hypotension in hemodialysis patients. Nephron, 2002, 90(4): 384-90.

[20] Vannorsdall, M. D., Hariachar, S., Hewitt, L. A. (2015). A randomized, placebo-controlled, phase 2 study of the efficacy and safety of droxidopa in patients with intradialytic hypotension. Postgrad Med., 2015, 127(2): 133-43. 